\title{
Estudo do comportamento termomecânico do aço inoxidável AISI 430 por meio da termografia por infravermelho
}

\author{
Study of the thermomechanical behavior of \\ AISI 430 stainless steel through infrared thermography
}

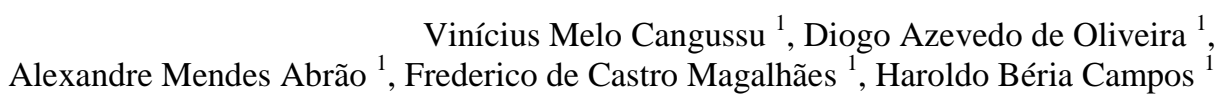

\begin{abstract}
${ }^{1}$ Programa de Pós-Graduação em Engenharia Mecânica, Universidade Federal de Minas Gerais, Av. Antônio Carlos, 6627, Pampulha, CEP: 31270-901 Belo Horizonte, MG, Brasil

e-mail: viniciusmelocangussu@gmail.com,diogoazev@yahoo.com.br, abrao@demec.ufmg.br, fredmag.castro@gmail.com
\end{abstract}

\section{RESUMO}

Este trabalho tem como objetivo investigar o aumento da temperatura em chapas de aço inoxidável AISI 430 durante o ensaio de tração para as seguintes taxas de deformação: 0,001; 0,01 e $0,1 \mathrm{~s}^{-1}$. Para registrar a evolução da temperatura até a fratura dos corpos de prova, foi utilizada uma termocâmera por infravermelho. Os resultados obtidos pela técnica da termografia por infravermelho mostraram um aumento gradual e uniforme da temperatura durante o encruamento do material e uma elevação drástica da temperatura nas regiões de estricção e fratura dos corpos de prova. Para a taxa de deformação de $0,1 \mathrm{~s}^{-1}$ foi observado o maior gradiente de temperatura entre a estricção localizada e a fratura $\left(110^{\circ} \mathrm{C}\right)$.

Palavras-chave: Aço inoxidável AISI 430, Termografia por infravermelho, Taxas de deformação, Temperatura.

\section{ABSTRACT}

This study aims to correlate the temperature increase induced by the strain rate of AISI 430 stainless steel sheets during the tensile test and considering the following strain rates: $0.001 ; 0.01$ and $0.1 \mathrm{~s}^{-1}$. In order to record the evolution of the temperature until the fracture of the specimens, an infrared thermographic camera was used. The results of infrared thermography showed a gradual and uniform increase in temperature during the work hardening of the material and a drastic temperature elevation in the regions of localized necking and fracture of the specimens. For the deformation rate of $0.1 \mathrm{~s}^{-1}$ the highest temperature gradient between localized necking and fracture was observed $\left(110^{\circ} \mathrm{C}\right)$.

Keywords: AISI 430 stainless steel, Infrared thermography, Strain rate, Temperature.

\section{INTRODUÇÃO}

Durante a conformação mecânica de chapas planas, a peça estampada pode estar sujeita a diferentes estados de deformações plásticas (biaxial, uniaxial e plana, por exemplo). Segundo BANABIC [1], a ocorrência de defeitos como fratura, estricção, empenamento, enrugamento e distorção de forma é relativamente comum durante o processamento das chapas metálicas que podem resultar no descarte do produto final. Dentre os fatores que afetam a estampabilidade de uma chapa plana tem-se: tamanho e geometria do blanque, geometria do ferramental, tipo de lubrificante, força do eventual prensa-chapa e a taxa de deformação, que influencia significativamente na estampabilidade do metal [2]. De um modo geral, a fabricação de uma determinada peça é bem-sucedida quando são empregadas baixas taxas de deformação, e, caso haja um aumento nessa taxa de deformação durante o processamento da chapa metálica, pode haver deformação plástica não uniforme, e, consequentemente, estricção localizada, como sugerem ALTAN e TEKKAYA [3].

Além disso, é sabido que quando um material metálico é deformado plasticamente, 95\% do trabalho mecânico de deformação por volume é convertido em calor. Uma parcela deste calor é conduzida para as ferramentas ou transferida para a atmosfera, porém, a parcela remanescente, é responsável pelo aumento da temperatura do componente trabalhado [4]. Os outros 5\% são responsáveis pelo movimento e aniquilação dos defeitos e da energia acumulada pela a criação de discordâncias na estrutura. Conforme HOSFORD e CADDELL [5], nos processos de conformação de chapas metálicas, nos 
quais são aplicadas altas taxas de deformação, é observado um apreciável aumento na temperatura, que em determinados materiais (aço inoxidável AISI 430), por exemplo, pode alterar o seu estado de deformação e suas propriedades mecânicas. Dessa forma, o conhecimento dos estados de deformação plástica, da distribuição da temperatura de chapas metálicas submetidas a diferentes taxas de deformação e das condições de transferência de calor são essenciais para a produção de uma peça isenta de defeitos de natureza mecânica e térmica.

Para estudar o aquecimento induzido durante a deformação plástica de um material podem ser utilizadas técnicas não destrutivas com e sem contato. A técnica não destrutiva com contato é caracterizada pela fixação de termopares junto ao material, enquanto que a sem contato adota o uso de câmeras termográficas. O uso de termopares para a medição de temperatura apresenta alguns inconvenientes como a necessidade de soldá-los na superfície do material a ser estudado e registrar apenas temperaturas pontuais [6]. Além disso, conforme HOSFORD e CADDELL [5], durante o processo de soldagem dos termopares podem ter sido geradas heterogeneidades superficiais, as quais afetam diretamente o estado de deformação uniforme.

A termografia por infravermelho é uma técnica de medição de temperatura sem contato em que a radiação infravermelha emitida por um objeto é registrada usando uma câmera infravermelha. A temperatura do objeto é medida a partir da intensidade da radiação usando a lei de Stefan-Boltzmann [7]. Para VILLAR et al. [8], embora a técnica da termografia por infravermelho seja bem conhecida na avaliação não destrutiva de amostras metálicas e na detecção de defeitos na soldagem de materiais, por exemplo, essa técnica começou a ser difundida apenas no final da década de 1970. Em relação às técnicas com contato, a termografia por infravermelho tem a vantagem de realizar medições de temperatura em áreas maiores que podem ser digitalizadas com alta confiabilidade e exatidão. Dentre os primeiros trabalhos relatados na área de monitoramento da temperatura de objetos submetidos a esforços de tração destaca-se WILBURN [9], no qual dois sistemas de radiômetro de infravermelho foram usados para monitorar os perfis de temperatura durante o ensaio de tração de aços ligados, demonstrando a viabilidade dessa técnica, por ser rápida e exata. HUANG et al. [10] monitoraram a temperatura durante a deformação elástica de aços com baixo e médio carbono. Em ambos os trabalhos experimentais, o ensaio de tração foi realizado empregando apenas uma taxa de deformação $\left(0,0001 \mathrm{~s}^{-1}\right)$. Além disso, os radiômetros usados por WILBURN [9] e HUANG et al. [10] tinham resolução limitada e registrava a temperatura média em grandes áreas projetadas. SACHEV e HUNTER [11] usaram o scanner AGA Thermovision 680 para medir o aumento da temperatura durante o ensaio de tração do aço Dual-Phase e de alta liga (HSLA). Os valores obtidos foram comparados com os valores previstos para condição teórica de aquecimento adiabático, a qual superestimou os valores medidos experimentalmente. Recentemente, os estudos termomecânicos que envolvem o uso da termografia por infravermelho restringem-se mais aos ensaios de tração, nos quais procura-se avaliar o aumento da temperatura durante as deformações elástica e plástica, na estricção e na fratura de diferentes materiais [12- 14]. Além disso, esses estudos auxiliam no desenvolvimento de modelos matemáticos capazes de predizer a temperatura em função do material, tensão, deformação e taxa de deformação até a tensão de resistência máxima do material e transformações de fase induzidas pela deformação plástica [15].

Tendo em vista a viabilidade e a exatidão dos resultados obtidos pela técnica da termografia por infravermelho, este trabalho visa investigar o aumento de temperatura mediante a deformação plástica por meio do ensaio de tração de chapas de aço inoxidável AISI 430 e o quanto as taxas de deformação influenciam nestes aumentos. Dessa forma, o conhecimento prévio do comportamento termomecânico do aço inoxidável AISI 430, que é largamente usado em diferentes setores da indústria de conformação de chapas, visa auxiliar o entendimento de sua estampabilidade quando conformado a frio, o que pode ser crucial para a produção de determinados produtos isentos de defeitos.

\section{MATERIAIS E MÉTODOS}

A composição química das chapas planas de aço inoxidável AISI 430 usadas para a confecção dos corpos de provas foi obtida por via úmida e o resultado é mostrado na Tabela 1. A composição química do material a ser testado está condizente com as especificações da AISI [16].

Tabela 1: Composição química das chapas de aço AISI 430 (\% em massa).

\begin{tabular}{lllll}
\hline $\mathbf{C}$ & $\mathbf{S i}$ & $\mathbf{M n}$ & $\mathbf{C r}$ & $\mathbf{N i}$ \\
\hline 0,06 & 0,4 & 1,68 & 18,1 & 9,1 \\
\hline $\max 0,15$ & $\max 0,50$ & $\max 1$ & $11,5-13,0$ & $\min 0,60$ \\
\hline
\end{tabular}

A Figura 1 representa de forma esquemática a configuração experimental para investigar o comportamento termomecânico do aço inoxidável AISI 430 submetido a esforços monotônicos com diferentes velocidades de deformação. Durante a realização do ensaio de tração são coletadas informações relativas à curva de fluxo e temperatura para posterior análise. 

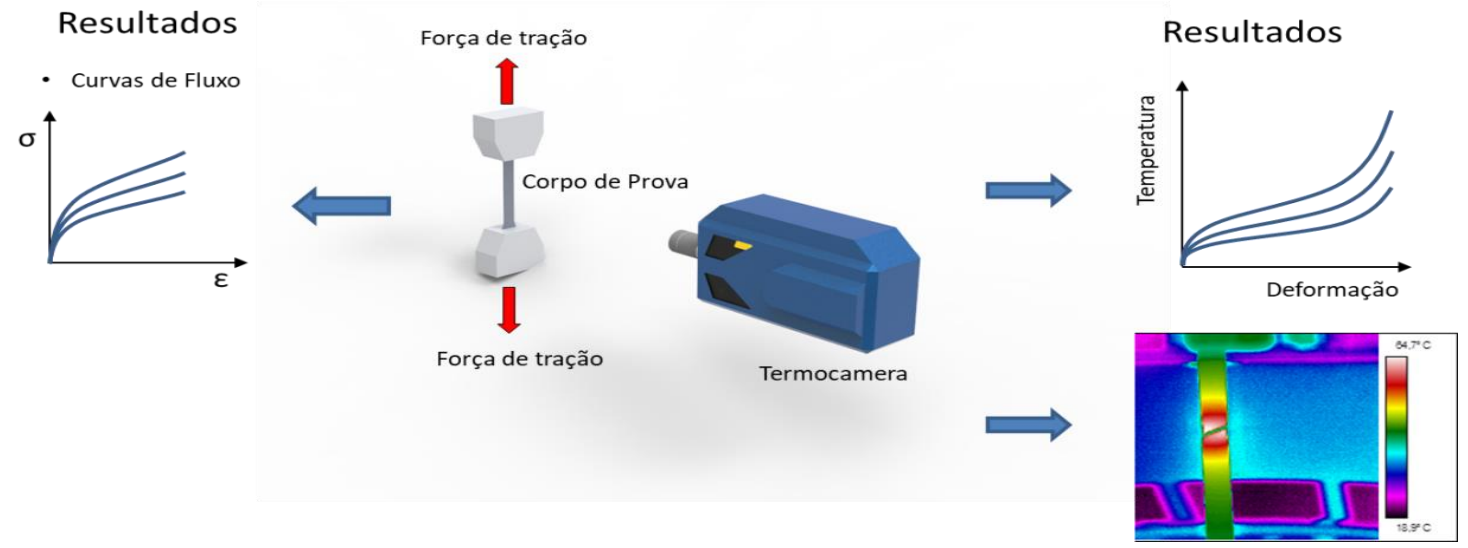

Figura 1: Representação esquemática do procedimento experimental.

Para analisar o comportamento termomecânico do aço inoxidável AISI 430, corpos de provas planos foram fabricados de acordo com a norma NBR 6152/2002 (Figura 2). A fim de evitar quaisquer alterações metalúrgicas durante a fabricação dos corpos de prova, esses foram cortados por jato de água. Para este estudo, foram retirados nove corpos de provas paralelos à direção de laminação de uma chapa plana com espessura nominal de 1,5 mm.

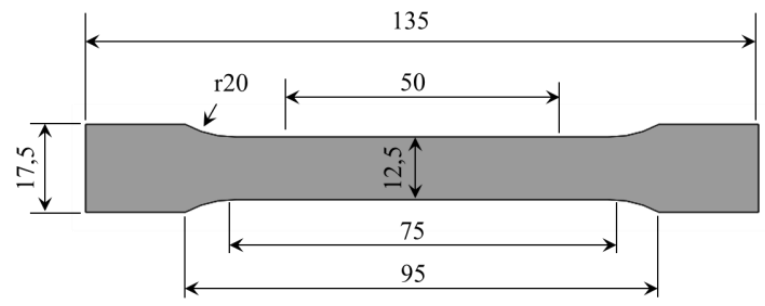

Figura 2: Dimensões dos corpos de prova para os ensaios de tração (em mm).

Os corpos de prova (dureza média de $200 \pm 5 \mathrm{HV}$ ), foram submetidos a esforços monotônicos trativos com diferentes velocidades de deformação $(5,50$ e $500 \mathrm{~mm} / \mathrm{min})$ a fim de se obter as seguintes taxas de deformação: 0,$001 ; 0,01 ; 0,1 \mathrm{~s}^{-1}$, respectivamente. Para cada velocidade de deformação foram utilizados três corpos de prova. Para a realização dos ensaios trativos foi utilizada a máquina universal de ensaios Shimadzu-AG-IS de $100 \mathrm{kN}$.

As medições dos gradientes de temperatura durante os ensaios de tração foram realizadas pela câmera infravermelha AGEMA 550 Elite, com objetivas de $20^{\circ} \times 20^{\circ}$, associada ao software Irwin Research 2.1 para registrar as imagens térmicas. Para evitar a influência do ângulo de visão, a câmera foi posicionada de forma que seu eixo permanecesse perpendicular às superfícies das amostras. A distância da câmera até cada amostra foi mantida em $500 \mathrm{~mm}$ para todos os ensaios e usou-se uma emissividade de 0,90 . As imagens térmicas foram adquiridas continuamente a uma taxa de 50 quadros por segundo durante os ensaios de tração e armazenadas digitalmente em um computador pessoal. Para melhorar a qualidade das imagens e diminuir possíveis ruídos causados por reflexos térmicos, os corpos de prova foram pintados na cor preta fazendo o uso de um corante acrílico preto fosco, visando garantir as condições de um corpo negro. Os ensaios termomecânicos foram realizados a uma temperatura ambiente de $25^{\circ} \mathrm{C} \pm 2{ }^{\circ} \mathrm{C}$ e umidade de 25 a $60 \% \mathrm{Hr}$.

\section{RESULTADOS E DISCUSSÃO}

Nesta seção será apresentada e discutida a evolução da temperatura máxima durante o ensaio de tração em relação às três taxas de deformação utilizadas.

A Figura 3 mostra o comportamento das curvas de tensão efetiva em função da deformação efetiva obtida para as chapas de aço inoxidável AISI 430 para as suas respectivas taxas de deformação. 


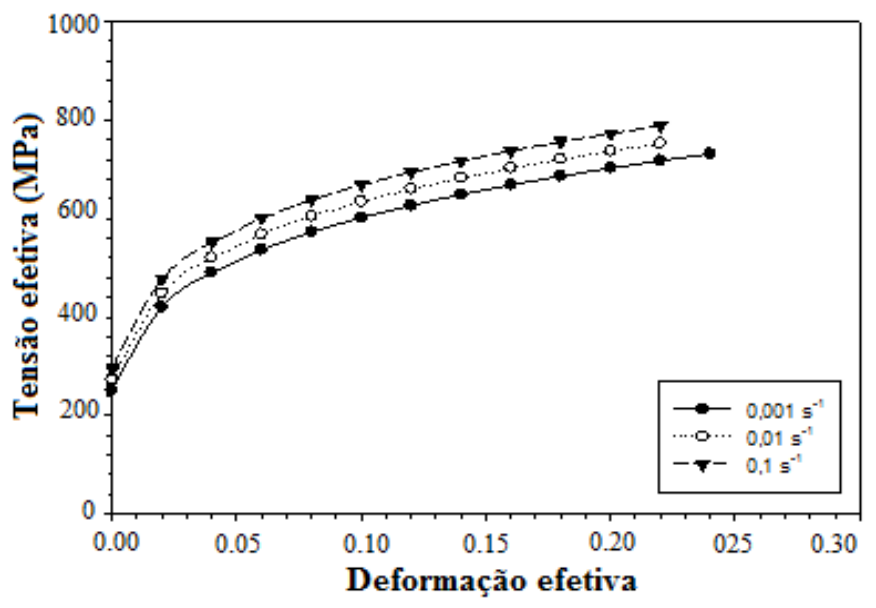

Figura 3: Evolução da tensão de engenharia para diferentes taxas de deformação do aço inoxidável AISI 430.

Conforme DIETER [4], quanto maior a taxa de deformação maior será a tensão de escoamento e resistência máxima do material. Para as taxas de deformação aplicadas no ensaio de tração do aço inoxidável AISI 430 foram obtidos os seguintes valores para a tensão limite de escoamento: $218 \pm 5,27 \mathrm{MPa}\left(0,001 \mathrm{~s}^{-1}\right) ; 236 \pm 2,30 \mathrm{MPa}\left(0,01 \mathrm{~s}^{-1}\right)$ e $256 \pm 7,34$ $\mathrm{MPa}\left(0,1 \mathrm{~s}^{-1}\right)$ e para tensão limite de resistência à tração: $527 \pm 20,05 \mathrm{MPa}\left(0,001 \mathrm{~s}^{-1}\right) ; 554 \pm 15,22 \mathrm{MPa}\left(0,01 \mathrm{~s}^{-1}\right)$ e $582 \pm$ $12,75 \mathrm{MPa}\left(0,1 \mathrm{~s}^{-1}\right)$. Em termos de encruamento do material, fez-se necessário determinar as curvas de fluxos para cada taxa de deformação. Para isso, foram determinadas as curvas de Hollomon: $\sigma=1006,3 \cdot \varepsilon^{0,223}\left(\mathrm{R}^{2}=0,998\right)$ para $0,001 \mathrm{~s}^{-1}$, $\sigma=1044,6 \cdot \varepsilon^{0,216}\left(\mathrm{R}^{2}=0,998\right)$ para $0,01 \mathrm{~s}^{-1}$ e $\sigma=1082,1 \cdot \varepsilon^{0,209}\left(\mathrm{R}^{2}=0,999\right)$ para $0,1 \mathrm{~s}^{-1}$.

Observando o expoente de encruamento das equações de Hollomon, pode-se perceber que para a taxa de deformação $0,001 \mathrm{~s}^{-1}$ apresentou o maior valor $(0,223)$. Em termos de estampabilidade, para essa taxa de deformação o aço inoxidável AISI 430 deformará mais uniformemente do que as outras taxas, confirmando as recomendações propostas por ALTAN e TEKKAYA [3].

As Figuras 4 a 6 mostram imagens térmicas registradas pela termocâmera durante o ensaio de tração até a ruptura do material para diferentes níveis de taxa de deformação e as suas respectivas temperaturas máximas a cada intervalo de tempo. Para uma mesma taxa de deformação, observou-se que em determinados ensaios as temperaturas induzidas pela deformação apresentaram em termos percentuais valores menores nas áreas de estricção $(\sim 25 \%)$ e fratura $(\sim 57 \%)$. Ao analisar esses corpos de prova, verificou que a tinta não aderiu adequadamente à superfície. De acordo com ROBISON et al. [17], as indicações de temperatura termográfica podem diferir ligeiramente entre as amostras devido a alguma incerteza no valor de emissividade com a tinta aplicada ( 0,90 em todos os casos), aplicação inadequada e a interferência de reflexos térmicos. 


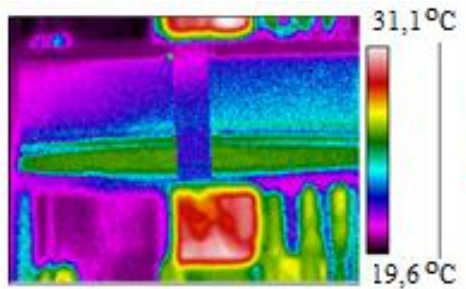

(a) Tempo: $0 \mathrm{~s}$ $\mathrm{T}_{\max }=23^{\circ} \mathrm{C}$

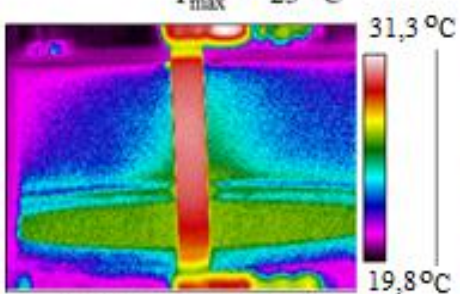

(d) Tempo: $4 \min 04 \mathrm{~s}$ $\mathrm{T}_{\max }=30,6^{\circ} \mathrm{C}$

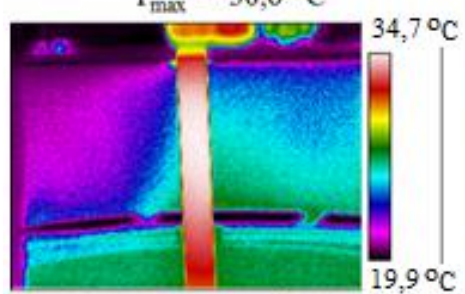

(g) Tempo: $8 \min 10 \mathrm{~s}$ $\mathrm{T}_{\max }=34,7^{\circ} \mathrm{C}$

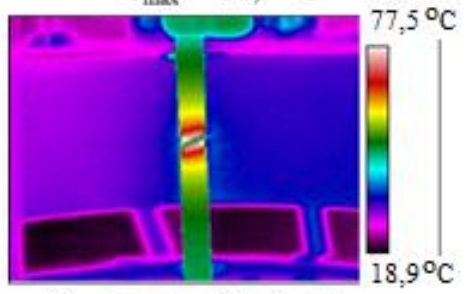

(j) Tempo: $12 \min 14 \mathrm{~s}$ $\mathrm{T}_{\max }=77,5^{\circ} \mathrm{C}$

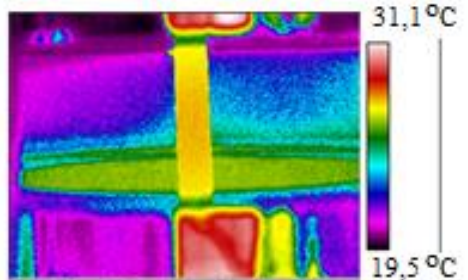

(b) Tempo: $1 \min 20 \mathrm{~s}$ $\mathrm{T}_{\max }=26,1^{\circ} \mathrm{C}$

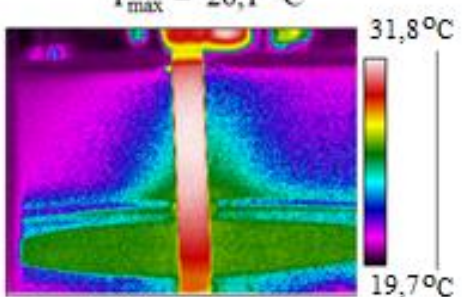

(e) Tempo: $5 \min 27 \mathrm{~s}$ $\mathrm{T}_{\max }=31,8^{\circ} \mathrm{C}$

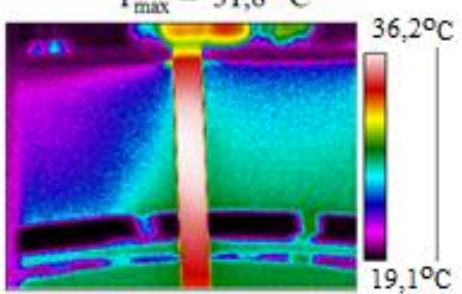

(h) Tempo: $9 \min 32 \mathrm{~s}$ $\mathrm{T}_{\max }=36,2^{\circ} \mathrm{C}$

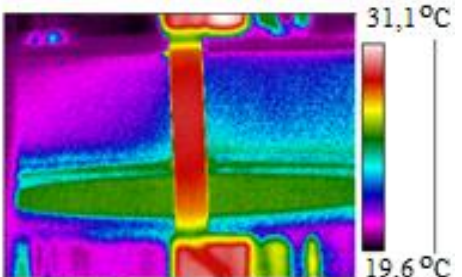

(c) Tempo: $2 \min 44 \mathrm{~s}$ $\mathrm{T}_{\max }=28,6^{\circ} \mathrm{C}$

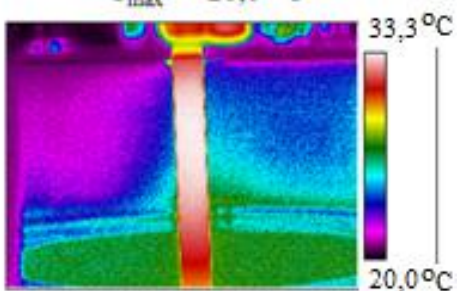

(f) Tempo: $6 \mathrm{~min} 48 \mathrm{~s}$ $\mathrm{T}_{\max }=33,3{ }^{\circ} \mathrm{C}$

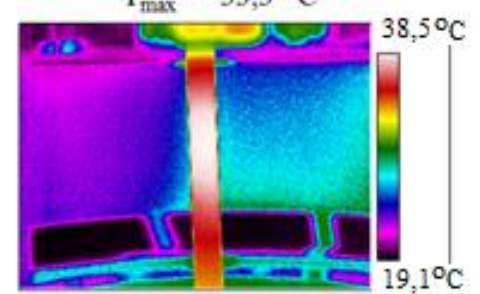

(i) Tempo: $10 \min 54 \mathrm{~s}$ $\mathrm{T}_{\max }=38,5^{\circ} \mathrm{C}$

Figura 4: Evolução da temperatura máxima durante o ensaio de tração para a taxa de deformação de $0,001 \mathrm{~s}^{-1}$. 


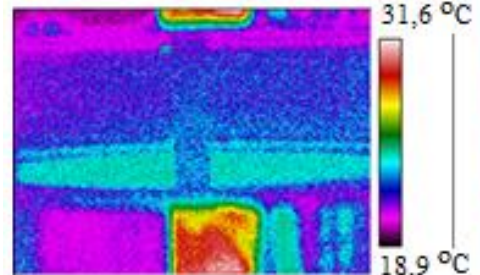

(a)

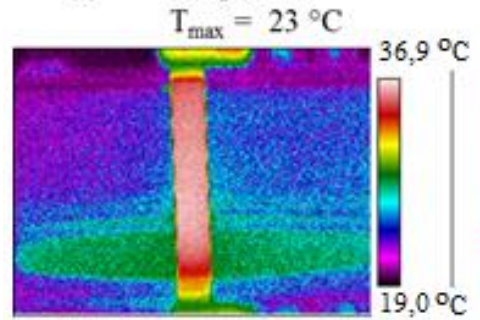

(d) Tempo: $19,90 \mathrm{~s}$

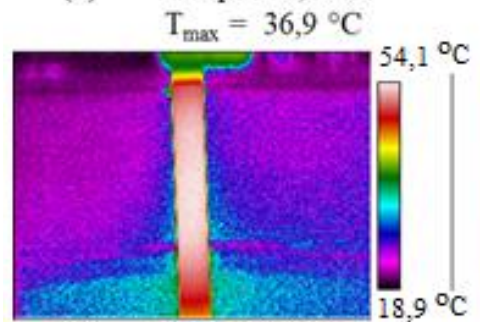

(g) Tempo: 40,12 $\mathrm{s}$ $\mathrm{T}_{\max }=54,1^{\circ} \mathrm{C}$

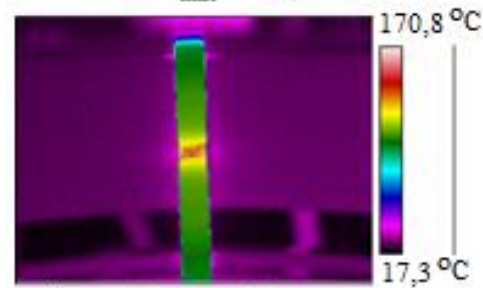

(j) Tempo: $60 \mathrm{~s}$

$\mathrm{T}_{\max }=170,8^{\circ} \mathrm{C}$

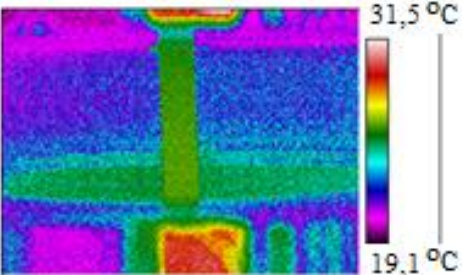

(b) Tempo: 6,46 $\mathrm{s}$ $\mathrm{T}_{\max }=28,4^{\circ} \mathrm{C}$

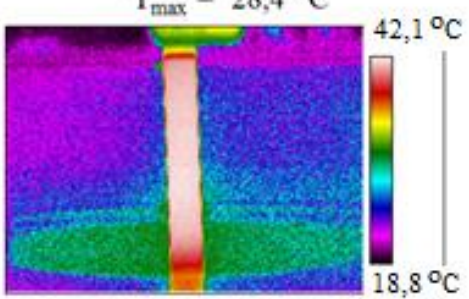

(e) Tempo: $26,59 \mathrm{~s}$
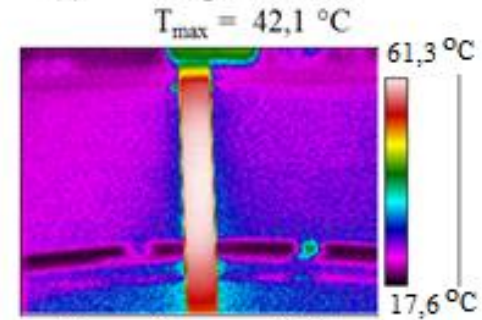

(h) Tempo: 46,83 $\mathrm{s}$ $\mathrm{T}_{\max }=61,3^{\circ} \mathrm{C}$

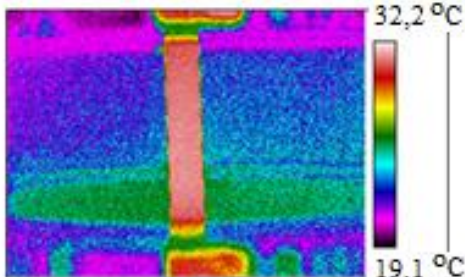

(c) Tempo: $13,22 \mathrm{~s}$

$\mathrm{T}_{\max }=32,2{ }^{\circ} \mathrm{C}$

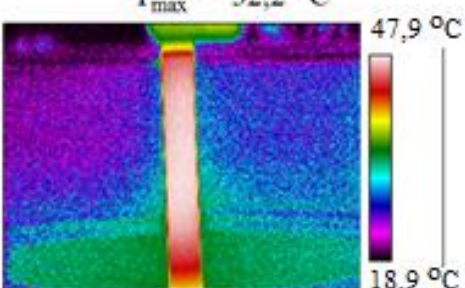

(f) Tempo: $33,43 \mathrm{~s}$

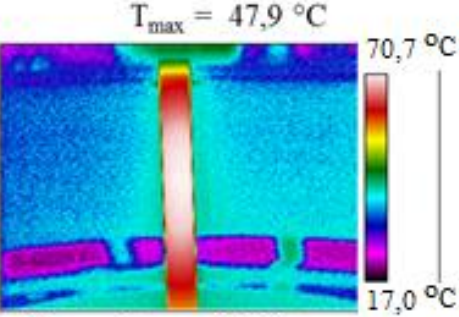

(i) Tempo: $53,50 \mathrm{~s}$

$\mathrm{T}_{\max }=70,7^{\circ} \mathrm{C}$

Figura 5: Evolução da temperatura máxima durante o ensaio de tração para a taxa de deformação de $0,01 \mathrm{~s}^{-1}$. 


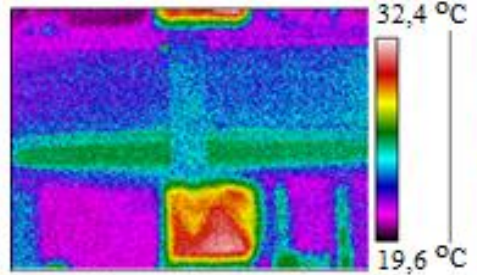

(a)

Tempo: $0 \mathrm{~s}$

$\mathrm{T}_{\max }=26,3^{\circ} \mathrm{C}$

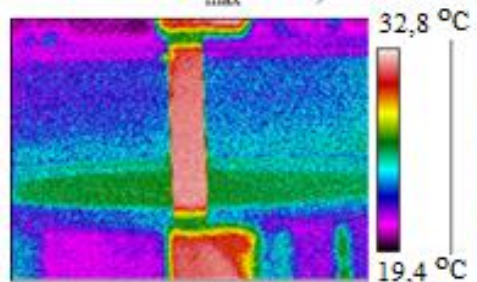

(d)

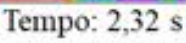

$\mathrm{T}_{\max }=32,8^{\circ} \mathrm{C}$

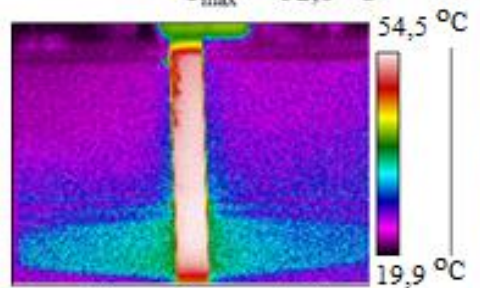

(g) Tempo: $4,66 \mathrm{~s}$ $\mathrm{T}_{\max }=54,5^{\circ} \mathrm{C}$

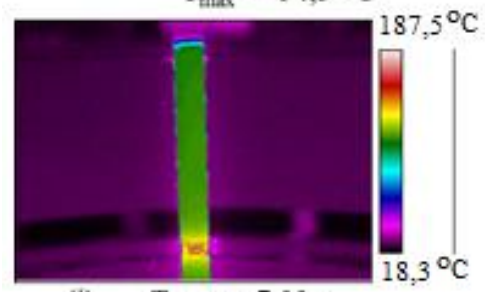

(j) Tempo: 7,00 $\mathrm{s}$

$\mathrm{T}_{\max }=187,5^{\circ} \mathrm{C}$

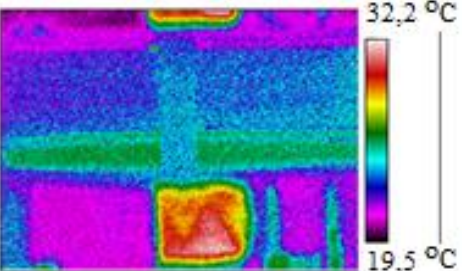

(b) Tempo: $0,76 \mathrm{~s}$ $\mathrm{T}_{\max }=26,7^{\circ} \mathrm{C}$

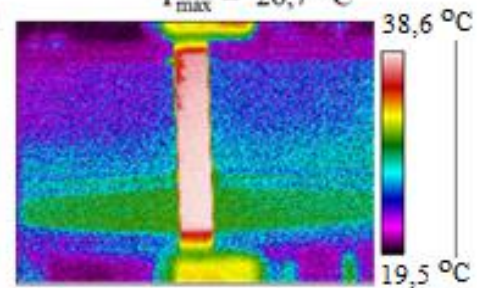

(e)

Tempo: $3,09 \mathrm{~s}$ $\mathrm{T}_{\max }=38,6^{\circ} \mathrm{C}$

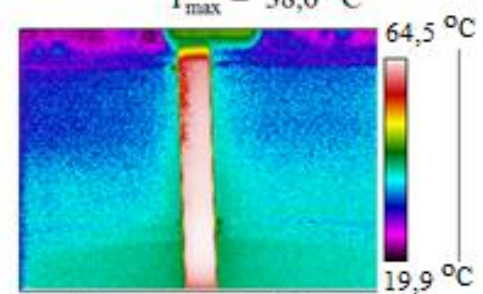

(h)

Tempo: $5,43 \mathrm{~s}$

$\mathrm{T}_{\max }=64,5^{\circ} \mathrm{C}$

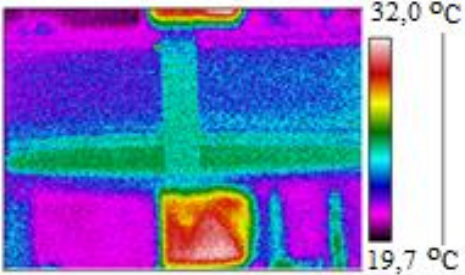

(c) Tempo: $1,54 \mathrm{~s}$

$\mathrm{T}_{\max }=26,8^{\circ} \mathrm{C}$

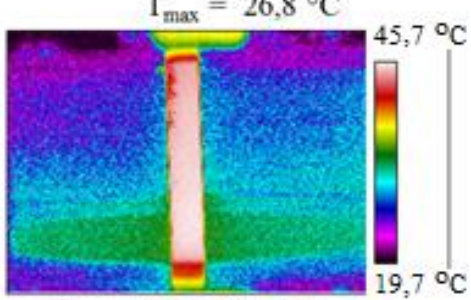

(f) Tempo: $3,88 \mathrm{~s}$

$\mathrm{T}_{\max }=45,7^{\circ} \mathrm{C}$

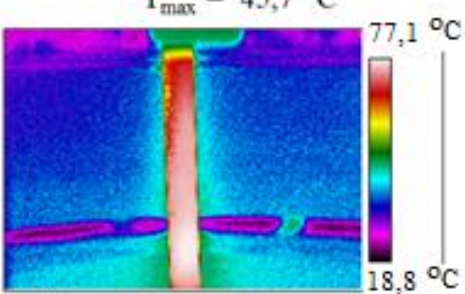

(i) Tempo: $6,21 \mathrm{~s}$

$\mathrm{T}_{\max }=77,1^{\circ} \mathrm{C}$

Figura 6: Evolução da temperatura máxima durante o ensaio de tração para a taxa de deformação de $0,1 \mathrm{~s}^{-1}$.

No ensaio de tração uniaxial, o material é submetido a uma deformação plástica progressiva e, em determinado momento, próximo à tensão máxima, aproximadamente 0,32 de deformação, inicia-se nucleação das cavidades internas, que é seguida pelo crescimento e o coalescimento dessas cavidades levando à fratura do material. Durante a deformação plástica, a energia armazenada é convertida em energia térmica, resultando no aumento da temperatura da amostra. O aumento de temperatura durante a estrição é decorrente da energia de deformação localizada. Além disso, a taxa de deformação varia exponencialmente com a tensão triaxial [18]. Portanto, o aumento da temperatura durante a deformação plástica do material é maior para a maior taxa de deformação. Sendo assim, analisando as imagens das Figuras 4(a) a 4(c), para todas as taxas de deformação, constatou-se que não ocorreram aumentos significativos nas temperaturas máximas, indicando que as deformações impostas aos corpos de prova encontravam-se no regime elástico (deformação reversível). Novamente para todas as taxas de deformação, as imagens das Figuras 4(d) a 4(h), indicam que os aumentos de temperatura foram praticamente lineares, $2{ }^{\circ} \mathrm{C}$ para $0,001 \mathrm{~s}^{-1}, 6{ }^{\circ} \mathrm{C}$ para $0,01 \mathrm{~s}^{-1}$ e $7{ }^{\circ} \mathrm{C}$ para $0,1 \mathrm{~s}^{-1}$, evidenciando que os corpos de prova estão sujeitos a deformações plásticas uniformes. Esse estado de deformação cessa quando é alcançada a resistência máxima.

A partir da Figura 4(i) até o instante da fratura do material (Figura $4 \mathrm{j}$ ) os aumentos foram significativos: $38^{\circ} \mathrm{C}$ para $0,001 \mathrm{~s}^{-1} ; 100{ }^{\circ} \mathrm{C}$ para $0,01 \mathrm{~s}^{-1}$ e $110^{\circ} \mathrm{C}$ para $0,1 \mathrm{~s}^{-1}$, indicando uma deformação não uniforme. $\mathrm{O}$ mesmo comportamento foi observado nas Figuras 5 e 6.

Analisando as imagens das Figuras 4(j), 5(j) e 6(j), independentemente da taxa de deformação, a técnica da termografia por infravermelho foi capaz de indicar a priori a região de falha (maior temperatura) durante a deformação dos corpos de prova. Em termos de comparação, a temperatura máxima na região da fratura do material submetido a uma taxa de deformação de $0,1 \mathrm{~s}^{-1}$ foi de $187,5^{\circ} \mathrm{C}$, isto é, $59 \%$ maior quando se aplicou uma taxa de $0,001 \mathrm{~s}^{-1}\left(77,5^{\circ} \mathrm{C}\right)$. Uma forma de avaliar esses perfis de aumento na temperatura nos regimes elástico, plástico e na região da fratura é sobrepondo as variações da tensão e da temperatura em função da deformação de engenharia (Figura 7). 

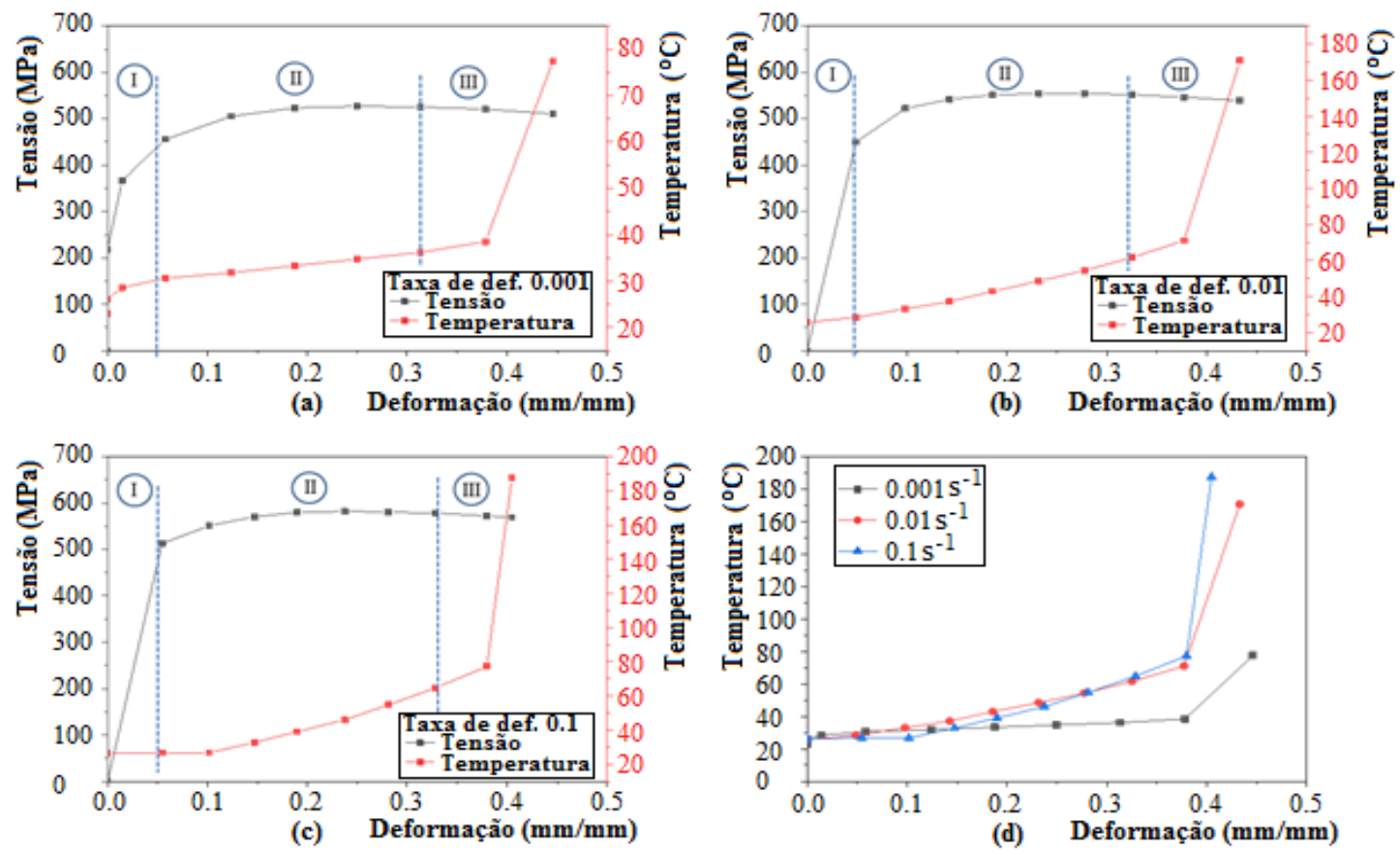

Figura 7: Tensão-temperatura em função da deformação: (a) taxa de deformação $0,001 \mathrm{~s}^{-1}$, (b) taxa de deformação $0,01 \mathrm{~s}^{-1}$, (c) taxa de deformação $0,1 \mathrm{~s}^{-1} \mathrm{e}(\mathrm{d})$ temperatura em função da deformação.

Avaliando os gráficos tensão-temperatura em função da deformação, para todas as taxas de deformação, as temperaturas compreendidas na região I, apresentaram pequenos aumentos, o que pode ser atribuído às tensões hidrostáticas que promovem as alterações de volume durante a deformação elástica. Embora exista um pequeno aumento na temperatura na região I, em geral o aumento de temperatura foi quase independente da taxa de deformação.

Na região II, fase do encruamento do material, a temperatura aumentou quase linearmente com a redução uniforme da seção transversal dos corpos de prova ao longo do seu comprimento. Para o intervalo entre 0,1 a 0,2 de deformação, a temperatura do aço inoxidável AISI 430 aumentou $2,7{ }^{\circ} \mathrm{C}$ para a taxa de $0,001 \mathrm{~s}^{-1}$ e $7{ }^{\circ} \mathrm{C}$ para as taxas de 0,01 e $0,1 \mathrm{~s}^{-1}$. De 0,2 de deformação até a resistência máxima do material (aproximadamente 0,25 de deformação para todas as taxas), os aumentos de temperatura continuaram lineares, porém, com um percentual maior: $8{ }^{\circ} \mathrm{C}$ para a taxa de $0,001 \mathrm{~s}^{-1}, 25^{\circ} \mathrm{C}$ para a taxa de $0,01 \mathrm{~s}^{-1}$ e $35^{\circ} \mathrm{C}$ para a taxa de $0,1 \mathrm{~s}^{-1}$. A partir da resistência máxima a deformação plástica torna-se instável, a redução da seção deixa de ser uniforme, dando início à formação da estricção difusa nos corpos de prova. Nessa etapa, a termografia por infravermelho revelou claramente um aumento mais acentuado na temperatura para todas as taxas de deformação. Segundo GOLASINSKI et al. [19], na região III, a deformação progride de forma acelerada com o aumento da taxa de deformação e o processo tende a ser adiabático. Sob tais condições, a geração de calor devido à deformação, principalmente após a estricção localizada, foi mais rápida que a difusão de calor em toda a amostra, resultando em um aumento de temperatura substancialmente maior para os experimentos com taxas de deformação mais altas. A geração adiabática de calor na estricção localizada também foi maior na região da fratura (Figura $7(\mathrm{~d})$ ): $77,5^{\circ} \mathrm{C}$ para a taxa de 0,001 $\mathrm{s}^{-1}$ e $170,8^{\circ} \mathrm{C}$ para a taxa de $0,01 \mathrm{~s}^{-1}$ e $187,5^{\circ} \mathrm{C}$ para a taxa de $0,1 \mathrm{~s}^{-1}$.

\section{CONCLUSÕES}

A aplicação da técnica da termografia por infravermelho para a medição do gradiente de temperatura do aço inoxidável AISI 430, submetido a esforços trativos com diferentes taxas de deformação, mostrou-se bastante promissora, uma vez que, foi capaz de registrar os gradientes térmicos nos regimes elástico e plástico e na região de fratura dos corpos de prova. No regime elástico (deformações reversíveis), o aumento da temperatura foi desprezível para todas as taxas de deformação. No regime plástico, onde há o encruamento do material, observou-se a influência das taxas de deformação mais elevadas $(0,01$ e $0,1 \mathrm{~s}^{-1}$ ) quando comparadas com a taxa de $0,001 \mathrm{~s}^{-1}$ no aumento da temperatura, principalmente após a resistência máxima do aço inoxidável AISI 430 ser exercida. Desde a formação da estricção localizada até a fratura dos corpos de prova, o aumento na temperatura foi dependente do aumento da taxa de deformação.

\section{AGRADECIMENTOS}

Os autores agradecem ao CNPq, CAPES e FAPEMIG pelo apoio à realização deste trabalho.

\section{BIBLIOGRAFIA}

[1] BANABIC, D., Sheet metal forming processes, $2^{\mathrm{a}}$ ed., Berlin. Springer-Verlag. 2010.

[2] KLOCKE, F., Manufacturing processes 4: forming, $1^{\text {a }}$ ed., Berlin. Springer-Verlag. 2013. 
[3] ALTAN, T., TEKKAYA, E., Sheet metal forming: fundamentals, 1ª ed., ASM International. 2012.

[4] DIETER, G.E., Mechanical metallurgy, $3^{\mathrm{a}}$ ed. 1986.

[5] HOSFORD, W., CADDELL, R., Metal forming: mechanics and metallurgy, $3^{\mathrm{a}}$ ed., Cambridge University. 2011

[6] BAGAVATHIAPPAN, S., LAHIRI, B.B., SARAVANAN, T., et al., "Infrared thermography for condition monitoring A review", Infrared Physics \& Technology, v. 60, pp. 35-65. 2013.

[7] PIECZYSKA, E., GOLASINSKI, K., MAJ, M., et al., "Yielding and strain localization effects in gum metal - a unique Ti alloy - investigated by digital image correlation and infrared thermography", Materialstoday: Proceedings, v. 12, pp. 235$238,2019$.

[8] VILLAR, M., GARNIER, C., CHABERT, F., et al., "In-situ infrared thermography measurements to master transmission laser welding process parameters of PEKK”, Optics and Lasers in Engineering, v. 106, pp. 94-104, 2018.

[9] WILBURN, K., “Temperature profiles observed in tensile specimens during physical test”, Mater. Eval., v. 35, pp. 28-31. 1977.

[10] HUANG, Y., XU, J., SHIH, C.H., “Application of infrared technique to research on tensile test”, Mater. Eval., v.38, pp. 76-79. 1980.

[11] SACHEV, A.K., HUNTER, J. E., “Thermal effects during uniaxial straining of steels", Metallurgical Transactions, v. 13A, pp. 1063-1067. 1982.

[12] JUAN, M.S., MARTÍN, O., SANTOS, F.J., et al., "Application of thermography to analyze the influence of the deformation speed in the forming process", Procedia Engineering, v. 63, pp. 821-828. 2013.

[13] HANEEF, T., LAHIRI, B.B., BAGAVATHIAAPPAN, S., et al., "Study of the tensile behavior of AISI type 304 stainless steel using acoustic emission and infrared thermography techniques", Journals of Materials Research and Technology, v. 4, pp. 241-253. 2015.

[14] SHARKEEV, Y.P., VAVILOV, V.P., BELYAVSKAYA, O.A., et al., "Analyzing deformation and damage of VT0,017-0 titanium in different structural states by using infrared thermography", J. Nondestruct. Eval., v. 35, pp. 42-47. 2016.

[15] MARTINEZ, J.A.R., PESCI, R., RUSINEK, A., "Experimental study on the martensitic transformation in AISI 304 steel sheets subject to tension under wide ranges of strain rate at room temperature", Mat. Sci. Eng, v. 528, pp. 5974-5982. 2016.

[16] ZHANG, Y., GUO, J., LI, Y., et al., "A comparative study between the mechanical and microstructural properties of resistance spot welding joints among ferritic AISI 430 and austenitic AISI 304 stainless steel ", J. Mater. Res. Technolo, v. 9, pp. $574-583,2020$.

[17] ROBISON, A.F., DULIEU-BARTON, J.M., QUINN, S., et al., "Paint coating characterization for thermoelastic stress analysis of metallic materials", Meas. Sci. Technol, v. 21, pp. 085502. 2010.

[18] MADIVALA, M., BLECK, W., "Strain rate dependent mechanical properties of TWIP steel", The Minerals, Metals \& Materials Society, v. 71, pp. 11291-1302. 2018.

[19] GOLASINSKI, K.M., PIECZYSKA, E.A., STASZCZAK, M., et al., "Infrared thermography applied for experimental investigation of thermomechanical couplings in Gum Metal”, QIRT J., v. 14, pp. 226-233. 2017.

\section{ORCID}

Vinícius Melo Cangussu

Diogo Azevedo de Oliveira

Alexandre Mendes Abrão

Frederico de Castro Magalhães

Haroldo Béria Campos https://orcid.org/0000-0002-3859-4559

https://orcid.org/0000-0001-9737-4911

https://orcid.org/0000-0003-2015-4077

https://orcid.org/0000-0003-2406-4407

https://orcid.org/0000-0002-9258-0019 